\title{
Plasma Steroids and Cardiorespiratory Fitness Response to Regular Exercise
}

\author{
Zihong He, Tuomo Rankinen, Arthur S. Leon, James S. Skinner, \\ André Tchernof, and Claude Bouchard
}

\begin{abstract}
The aim of this report is to evaluate the relationships between baseline levels of adrenal, gonadal and conjugated steroids and baseline cardiorespiratory fitness, as assessed by maximal oxygen uptake $\left(\mathrm{VO}_{2} \mathrm{max}\right)$, as well as its response to a standardized exercise program. To address this aim we used a subset of the HERITAGE Family Study ( $\mathrm{N}=448)$. In men, significant positive associations were found between baseline $\mathrm{VO}_{2} \mathrm{max} / \mathrm{kg}$ weight and plasma levels of androsterone glucuronide (ADTG), dihydrotesterone (DHT), 17 hydroxy progesterone (OHPROG), sex hormone binding globulin (SHBG), and testosterone (TESTO), and negative association with aldosterone (ALDO). In women, only the free androgen index (FAI) was negatively associated with baseline $\mathrm{VO}_{2} \mathrm{max} / \mathrm{kg}$ weight. Neither baseline plasma steroid levels nor SHBG concentrations were associated with the gains in $\mathrm{VO}_{2}$ max resulting from exposure to the 20-week aerobic exercise program after adjustment for baseline values, age and ethnicity (white or black). We conclude that baseline plasma steroid levels are only weakly associated with individual differences in cardiorespiratory fitness in the sedentary state in men but not in women, whereas no association could be detected with trainability, as defined by the change in $\mathrm{VO}_{2} \mathrm{max}$ with the exercise program.
\end{abstract}

\section{Z. He}

Human Genomics Laboratory, Pennington Biomedical Research Center,

Baton Rouge, LA, USA

Department of Biology, China Institute of Sport Science, Beijing, China

T. Rankinen $\bullet$ C. Bouchard $(\square)$

Human Genomics Laboratory, Pennington Biomedical Research Center,

Baton Rouge, LA, USA

e-mail: claude.bouchard@pbrc.edu

\section{A. S. Leon}

School of Kinesiology, University of Minnesota, Minneapolis, MN, USA

J. S. Skinner

Department of Kinesiology, Indiana University, Bloomington, IN, USA

A. Tchernof

School of Nutrition, Laval University, Quebec City, QC, Canada

(C) The Author(s) 2017

B. Spiegelman (ed.), Hormones, Metabolism and the Benefits of Exercise,

Research and Perspectives in Endocrine Interactions,

https://doi.org/10.1007/978-3-319-72790-5_3 


\section{Introduction}

The ongoing global epidemic of chronic non-communicable diseases (NCDs) is related to changes in lifestyle, including low physical activity (PA) levels. Physical inactivity is a major public health challenge (Engberg et al. 2012) and has been defined as the fourth leading cause of death worldwide (Kohl et al. 2012). The health benefits of regular PA are well established, and elimination of physical inactivity would remove between 6 and 10\% of NCDs and increase life expectancy (Lee et al. 2012). Moreover, cardiorespiratory fitness (CRF) is a strong predictor of health and longevity (United States Department of Health and Human Services 2008). There are large individual differences in CRF among adults who are sedentary and who have a history of not engaging in regular exercise (Bouchard et al. 2015). The response of CRF to regular exercise is also highly variable, even when the exercise prescription is highly standardized and when compliance is not an issue (Skinner et al. 2001). As shown by the findings of the HERITAGE Family Study, there are many factors contributing to variation in CRF exercise training response (Sarzynski et al. 2016). However, little is known about the relationships between plasma levels of steroid hormones and CRF in the sedentary state or in response to regular exercise in men or women.

Steroid hormones are mainly synthesized from cholesterol in the gonads and adrenal glands but some are also produced in other tissues such as skeletal muscle (Sato and Lemitsu 2015), adipose tissue, liver and others (Luu-The and Labrie 2010; Labrie 2015). Steroid hormones can be grouped into two classes, corticosteroids and sex steroids. Within those two classes, there are five types of hormones depending on the receptors to which they bind: glucocorticoids, mineralocorticoids, androgens, estrogens, and progestogens. Steroid hormones are generally carried in the blood, bound to specific carrier proteins such as sex hormone-binding globulin (SHBG; Hammond 2016) or corticosteroid-binding globulin (Meyer et al. 2016).

Steroid hormones exert a wide variety of effects on cardiorespiratory function. In brief, corticosteroids help mediate the stress response and promote energy replenishment and efficient cardiovascular function (Nicolaides et al. 2015). They also regulate muscle function by acting on muscle mass and strength (Hasan et al. 2012). Mineralocorticoids contribute to the regulation of blood pressure and participate in the regulation of cardiac and vascular function. The mineralocorticoid aldosterone (ALDO) is a key regulator of water and electrolyte homeostasis. Clinical trials have shown the beneficial effects of ALDO antagonists in chronic heart failure and postmyocardial infarction treatment (Lother et al. 2015). Long-term infusion of mineralocorticoid (ALDO) in mice resulted in elevation of plasma interleukin-1 $\beta$ levels and vascular abnormalities (Bruder-Nascimento et al. 2016). Androgens enhance skeletal muscle mass by promoting the enlargement of skeletal muscle cells (SinhaHikim et al. 2004). Muscle steroid hormone levels were shown to be positively 
correlated with muscle strength and cross-sectional area (Sato et al. 2014). Also, androgens inhibit the ability of adipocytes to store lipids by blocking a signal transduction pathway (Singh et al. 2006). Androgen deficiency has been shown to be a major risk factor for several disorders, including obesity, metabolic syndrome, and ischemic heart disease (Pongkan et al. 2016). The CARDIA Male Hormone Study showed that there are associations of androgens with PA and fitness in young black and white men (Wolin et al. 2007). Estrogens have vasculo-protective actions that are thought to prevent atherosclerosis (Reslan and Khalil 2012). Estrogens contribute to the regulation of the delicate balance between fighting infections and protecting arteries from damage, thus lowering the risk of cardiovascular disease (Meyer and Barton 2016). Some cardiovascular effects of estrogens may be counteracted by progestogens (Haddock et al. 2000; Group 2006). Progestogens have favorable effects on lipid, glucose and insulin profiles (Group 2006). Higher sex hormone binding globulin (SHBG) concentration was shown to be associated with a more favorable cardiovascular disease (CVD) risk profile, independent of total testosterone (Canoy et al. 2014).

A significant positive correlation has been observed between the changes in serum testosterone levels and the number of steps executed on a daily basis; this finding suggests that the level of PA affects serum testosterone concentrations in overweight and obese men (Kumagai et al. 2016). Steroid hormones are responsive to acute and chronic endurance exercise. Both acute and chronic exercise influence circulating steroid hormone levels (Sato and Lemitsu 2015) and SHBG (Kim and Kim 2012; Ennour-Idrissi et al. 2015) and activate local steroidogenesis in skeletal muscle (Sato and Lemitsu 2015).

In the present report, we focus on the relationships between plasma levels of adrenal, gonadal and conjugated steroids in the sedentary state and baseline (intrinsic) $\mathrm{CRF}$, as assessed by maximal oxygen uptake $\left(\mathrm{VO}_{2} \mathrm{max}\right)$, as well as its response to a standardized exercise program taking into account factors such as age, gender, ethnicity, and baseline characteristics when appropriate.

\section{Methods}

\section{Subjects}

The HERITAGE Family Study cohort has been previously described (Bouchard et al. 1995). A total of 488 adults with complete steroid hormones and $\mathrm{VO}_{2} \mathrm{max}$ data, who were fully compliant with the 20-week HERITAGE aerobic exercise program, were available for the present study. The study protocol had been previously approved by the institutional review board at each of the four clinical centers of HERITAGE. Informed written consent was obtained from each subject. 


\section{Anthropometric and Body Composition Measurements}

Body weight and height were measured following standardized procedures. Body density was measured using the hydrostatic weighing technique. The mean of the highest three (of 10) measurements was used in the calculation of percent body fat from body density using the equation of Siri (1956). Fat mass was obtained by multiplying body weight by percent body fat. These measurements have been shown to be highly reproducible, with no difference between clinical centers or drift over time in the course of data collection (Wilmore et al. 1997).

\section{Aerobic Exercise Training Program}

Each subject in the HERITAGE study exercised three times per week for 20 weeks on cycle ergometers. The intensity of the training was customized for each individual on the basis of heart rate (HR) and $\mathrm{VO}_{2}$ max measurements taken at a baseline maximal exercise test. Details of the exercise training protocol can be found elsewhere (Bouchard et al. 1995). Briefly, subjects trained at the HR associated with $55 \%$ of baseline $\mathrm{VO}_{2}$ max for 30 min per session for the first 2 weeks. The duration and intensity were gradually increased every 2 weeks, until reaching $50 \mathrm{~min}$ and $75 \%$ of the $\mathrm{HR}$ associated with baseline $\mathrm{VO}_{2} \max$. This level was maintained for the final six weeks of training. All training was performed on Universal Aerobicycles (Cedar Rapids, IA) and power output was controlled by direct HR monitoring using the Universal Gym Mednet (Cedar Rapids, IA) computerized system. The protocol was standardized across all four clinical centers and supervised to ensure that the equipment was working properly and that participants were compliant with the protocol.

\section{$\mathrm{VO}_{2} \max$ Measurement}

Two maximal exercise tests to measure $\mathrm{VO}_{2}$ max were performed on two separate days at baseline and again on two separate days after training using a SensorMedics 800S (Yorba Linda, CA) cycle ergometer and a SensorMedics 2900 metabolic measurement cart (Skinner et al. 2000). The tests were conducted at about the same time of day, with at least $48 \mathrm{~h}$ between the two tests. In the first test, subjects exercised at a power output of $50 \mathrm{~W}$ for $3 \mathrm{~min}$, followed by increases of $25 \mathrm{~W}$ every 2 min until volitional exhaustion. For older, smaller, or less fit individuals, the test was started at $40 \mathrm{~W}$, with increases of 10-20 W every 2 min thereafter. In the second test, subjects exercised for $10 \mathrm{~min}$ at an absolute $(50 \mathrm{~W})$ and at a relative power output equivalent to $60 \% \mathrm{VO}_{2} \max$. They then exercised for $3 \mathrm{~min}$ at a relative power output that was $80 \%$ of their $\mathrm{VO}_{2} \mathrm{max}$, after which resistance was increased to the highest 
power output attained in the first maximal test. If the subjects were able to pedal after $2 \mathrm{~min}$, power output was increased every 2 min thereafter until they reached volitional fatigue. The average $\mathrm{VO}_{2}$ max from these two sets was taken as the $\mathrm{VO}_{2}$ max for that subject and used in analyses if both values were within $5 \%$ of each other. If they differed by $>5 \%$, the higher $\mathrm{VO}_{2} \max$ value was used.

\section{Plasma Steroid Hormone and SHBG Concentrations}

The hormonal assays have been previously described (Couillard et al. 2000; Ukkola et al. 2001). Fourteen steroid hormones or their derivatives and SHBG concentrations were assayed. Table 1 provides the full name of each hormone, the abbreviations used in the present report and a brief comment on the source of production or

Table 1 Description of steroid hormones assayed in the HERITAGE Family Study

\begin{tabular}{|c|c|c|}
\hline & Name (unit) & Notes and sources \\
\hline \multicolumn{3}{|c|}{ I: Steroids in the 19-carbon family (androstanes) and their derivatives } \\
\hline \multicolumn{3}{|c|}{ Adrenal androgen precursors } \\
\hline DHEA & Dehydroepiandrosterone (nmol/L) & Source: Adrenals \\
\hline DELTA4 & Androstenedione (nmol/L) & $\begin{array}{l}\text { Source: Adrenals } \\
\text { Intermediate in synthesis of TESTO, DHT, E2 }\end{array}$ \\
\hline DHEAS & DHEA sulfate (nmol/L) & $\begin{array}{l}\text { Sulfated form of DHEA } \\
\text { Most abundant steroid in circulation }\end{array}$ \\
\hline DHEAE & DHEA fatty acid ester (nmol/L) & A second form of DHEA ester \\
\hline \multicolumn{3}{|c|}{ Active androgens } \\
\hline TESTO & Testosterone (nmol/L) & Source: Mainly by testicles \\
\hline DHT & Dihydrotesterone (nmol/L) & $\begin{array}{l}\text { Derived from TESTO or adrenal androgens } \\
\text { precursors in multiple tissues }\end{array}$ \\
\hline \multicolumn{3}{|c|}{ Androgen metabolites } \\
\hline DIOLG & $\begin{array}{l}\text { Androstane } 3 \alpha 17 \beta \text { diol glucuronide } \\
(\mathrm{nmol} / \mathrm{L})\end{array}$ & Metabolite of TESTO and DHT \\
\hline ADTG & Androsterone glucuronide (nmol/L) & Metabolite of TESTO and DHT \\
\hline \multicolumn{3}{|c|}{ II: Pregnanes, Progestanes, and Estradiol } \\
\hline PREGE & $\begin{array}{l}\text { Pregnenolone fatty acid ester } \\
(\mathrm{nmol} / \mathrm{L})\end{array}$ & $\begin{array}{l}\text { Derived from PREG in HDL particles and } \\
\text { other sites }\end{array}$ \\
\hline PROG & Progesterone (nmol/L) & Source: Mainly in the ovaries \\
\hline OHPROG & 17 hydroxy progesterone (nmol/L) & Derived from PROG in adrenals and gonads \\
\hline E2 & Estradiol (pmol/L) & Source: ovaries and other tissues \\
\hline \multicolumn{3}{|c|}{ III: Aldosterone, Cortisol, SHBG and FAI } \\
\hline ALDO & Aldosterone (nmol/L) & Source: adrenal cortex \\
\hline CORT & Cortisol (nmol/L) & Source: adrenal cortex \\
\hline SHBG & $\begin{array}{l}\text { Sex hormone binding globulin } \\
(\mathrm{nmol} / \mathrm{L})\end{array}$ & $\begin{array}{l}\text { Peptide transporting TESTO and E2 } \\
\text { Source: mainly liver }\end{array}$ \\
\hline FAI & Free androgen index & Calculated as TESTO/SHBG $* 100$ \\
\hline
\end{tabular}


transformation of the hormones and their precursors. On 2 consecutive days, two blood samples were obtained after a 12-h fast pre- and post- exercise program. For eumenorrheic women, all samples were obtained in the early follicular phase of the menstrual cycle. None of the women of reproductive age had dramatically irregular menstrual cycles, as determined by questionnaire and during an interview. After centrifugation, aliquots were frozen at $-80{ }^{\circ} \mathrm{C}$. For nonconjugated steroids (see Table 1 for abbreviations), ALDO, dehydroepiandrosterone (DHEA) and testosterone (TESTO) were differentially extracted with hexane-ethyl acetate. Petroleum ether was used for the extraction of androstenedione (DELTA4) and dihydrotesterone (DHT). In-house RIAs were used to measure the levels of these four steroids. Progesterone, 17 hydroxy progesterone (OHPROG), cortisol (CORT), estradiol (E2), and DHEA sulfate (DHEAS) were assayed using commercial kits (Diagnostics Systems Lab, Webster, TX, USA). For glucuronide [androsterone glucuronide (ADTG) and androstane 3 $\alpha 17 \beta$ diol glucuronide (DIOLG)] and ester [DHEA fatty acid ester (DHEAE) and prenenolone fatty acid ester (PREGE)] conjugated steroids, ethanol extraction was performed, followed by $\mathrm{C} 18$ column chromatography. Glucuronide conjugates were submitted to hydrolysis with $\beta$-glucuronidase (Sigma Co., St. Louis, MO, USA). Fatty acid derivatives were submitted to saponification. Steroids were then separated by elution on LH-20 columns and measured by RIA. SHBG was determined with an IRMA-Count solid phase immunoradiometric assay using 125I (Diagnostics Systems Laboratories, Inc.). All assays were performed in the laboratory of Dr. Alain Belanger, Molecular Endocrinology, Laval University Medical Center (CHUL), Québec, Canada.

\section{Statistical Analysis}

The present study is based on sedentary adults from the HERITAGE Family Study who had complete baseline hormonal data. The mean of two measurements both before and after the exercise program has been used for all hormones and SHBG levels. Data of men and women were analyzed separately. Pearson productmoment correlation coefficients were used to quantify the relationships between baseline $\mathrm{VO}_{2} \max$ (after adjustment for age and ethnicity) and its exercise training response (after adjustment for baseline, age and ethnicity) with fasting plasma steroid hormone, SHBG concentrations and the free androgen index (FAI). ANCOVA was used to compare each steroid, SHBG and FAI across quartiles of baseline $\mathrm{VO}_{2}$ max or its training response, with age and ethnicity as covariates. ANCOVA was used to compare the difference between the lowest $5 \%$ of the TESTO distribution and the men in the fourth quartile and between the highest $5 \%$ of the E2 distribution versus the women in the first quartile, with age and ethnicity as covariates. All analyses were performed using the SAS statistical package (SAS Institute, Inc., Cary, NC). Significance level was set at a more conservative p-value threshold of $<0.01$. 
Table 2 Reproducibility of fasting steroid hormone levels in three HERITAGE ancillary studies

\begin{tabular}{|c|c|c|c|c|c|c|}
\hline & \multicolumn{6}{|c|}{ Intraclass correlation coefficient } \\
\hline & \multicolumn{2}{|c|}{ Reliability of assay ${ }^{\mathrm{a}}$} & \multicolumn{2}{|c|}{ HERITAGE test-retest ${ }^{\mathrm{b}}$} & \multicolumn{2}{|c|}{$\begin{array}{l}\text { Three-day quality } \\
\text { control }^{c}\end{array}$} \\
\hline & $\begin{array}{l}\text { Males } \\
(\mathrm{N}=35)\end{array}$ & $\begin{array}{l}\text { Females } \\
(\mathrm{N}=25)\end{array}$ & $\begin{array}{l}\text { Males } \\
(\mathrm{N}=325)\end{array}$ & $\begin{array}{l}\text { Females } \\
(\mathrm{N}=420)\end{array}$ & $\begin{array}{l}\text { Males } \\
(\mathrm{N}=35)\end{array}$ & $\begin{array}{l}\text { Females } \\
(\mathrm{N}=25)\end{array}$ \\
\hline ADTG & 0.81 & 0.95 & 0.91 & 0.93 & 0.77 & 0.96 \\
\hline ALDO & 0.95 & 0.97 & 0.70 & 0.75 & 0.79 & 0.40 \\
\hline CORT & 0.98 & 0.96 & 0.52 & 0.88 & 0.55 & 0.70 \\
\hline DELTA4 & 0.97 & 0.98 & 0.91 & 0.94 & 0.95 & 0.93 \\
\hline DHEA & 0.97 & 0.97 & 0.76 & 0.80 & 0.86 & 0.71 \\
\hline DHEAE & 0.77 & 0.94 & 0.79 & 0.85 & 0.79 & 0.82 \\
\hline DHEAS & 0.97 & 0.98 & 0.96 & 0.97 & 0.94 & 0.92 \\
\hline DHT & 0.96 & 0.86 & 0.93 & 0.83 & 0.95 & 0.86 \\
\hline DIOLG & 0.80 & 0.97 & 0.96 & 0.93 & 0.73 & 0.98 \\
\hline E2 & 0.91 & 0.98 & 0.59 & 0.84 & 0.86 & N/A \\
\hline OHPROG & 0.98 & 0.96 & 0.86 & 0.80 & 0.90 & 0.74 \\
\hline PREGE & 0.89 & 0.87 & 0.83 & 0.86 & 0.69 & 0.79 \\
\hline PROG & 0.92 & 0.99 & 0.90 & 0.84 & 0.79 & N/A \\
\hline SHBG & 0.98 & 0.99 & 0.97 & 0.97 & 0.98 & 0.98 \\
\hline TESTO & 0.97 & 0.95 & 0.95 & 0.90 & 0.95 & 0.92 \\
\hline
\end{tabular}

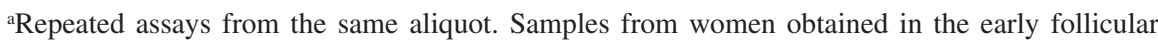
phase

${ }^{\mathrm{b}}$ Test-retest from sample drawn on two different days. Samples from women obtained in the early follicular phase

${ }^{\mathrm{c}}$ From samples tested three times in 3 weeks; menstrual cycle phase was not controlled in the female sample

\section{Results}

In the HERITAGE Family Study research program, three ancillary studies focusing on the within-subject variance and the reproducibility of test data were executed. Table 2 summarizes the main findings from these three sources for the steroid hormones and SHBG concentrations using the intraclass coefficients for repeated measures. In study 1, each assay was repeated from samples drawn from the same aliquot. Blood samples were drawn in the fasted state and those from eumenorrheic women were obtained in the early follicular phase. In study 2 , the test-retest data were from samples drawn on two different days in the fasted state. Again, samples from eumenorrheic women were obtained in the early follicular phase. In study 3, samples were drawn in the fasted state three times in 3 weeks. However, the menstrual cycle phase was not controlled for in the female sample of the latter study. Globally, the results of these reproducibility studies indicate that the within-subject variation in hormone and SHBG levels was quite small compared to the betweensubject fluctuations. The assays were quite reliable, as revealed by the very high intraclass coefficients for repeated assays on samples drawn from the same aliquot. 
Table 3 Basic characteristics of sedentary males and females

\begin{tabular}{l|r|l|l|l|l|l}
\hline & \multicolumn{5}{l}{ Men } & \multicolumn{2}{l}{ Women } \\
\cline { 2 - 7 } & \multicolumn{1}{l|}{ N } & Age & BMI $\left(\mathrm{kg} / \mathrm{m}^{2}\right)$ & \multicolumn{1}{l}{ N } & Age & BMI $\left(\mathrm{kg} / \mathrm{m}^{2}\right)$ \\
\hline All & 244 & $36 \pm 14$ & $26.5 \pm 4.4$ & 244 & $35 \pm 14$ & $25.1 \pm 25.0$ \\
\hline Blacks & 61 & $33 \pm 11$ & $26.7 \pm 4.1$ & 59 & $33 \pm 12$ & $27.2 \pm 5.8$ \\
\hline Whites & 183 & $37 \pm 15$ & $26.4 \pm 4.5$ & 185 & $35 \pm 14$ & $24.5 \pm 4.6$ \\
\hline 17-29 years & 114 & $23 \pm 4$ & $24.7 \pm 4.3$ & 121 & $22 \pm 3$ & $23.5 \pm 4.8$ \\
\hline 30-49 years & 74 & $40 \pm 7$ & $28.3 \pm 3.7$ & 75 & $41 \pm 6$ & $25.8 \pm 4.4$ \\
\hline 50-65 years & 56 & $56 \pm 4$ & $27.8 \pm 4.3$ & 48 & $55 \pm 4$ & $28.0 \pm 5.0$ \\
\hline
\end{tabular}

Mean \pm SD

This finding is particularly true for the steroids of high interest in the present paper, such as DHEA and DHEAS with coefficients $>0.97$, DHT and TESTO $>0.86$, E2 and PROG $>0.91$ and SHBG $>0.95$, all in both genders. When the day-to-day variation (plus the technical error of the assays) was considered in studies 2 and 3 , all coefficients were high $(>0.70)$, with the notable exception of CORT in males $(\sim 0.50)$.

Table 3 shows the physical characteristics of subjects stratified on the basis of age, gender and ethnicity. There were 244 adult subjects for each gender. About $25 \%$ of the subjects were blacks, with no difference between men and women. The male cohort was slightly overweight and heavier than the females, with the exception of black women.

Table 4 shows the baseline value of steroid hormones and SHBG in men and women. Mean and median values plus 95\% confidence intervals and intervals between the first and fourth quartiles of the distributions are presented. Testing for skewness of distributions revealed that there was no indication of a major skewness problem with any of the variables.

Table 5 describes the $\mathrm{VO}_{2}$ max at baseline and training response. Shown are baseline $\mathrm{VO}_{2}$ max per $\mathrm{kg}$ of body weight and $\mathrm{kg}$ of fat-free mass. The most important inclusion criterion of the HERITAGE participants was that they needed to be confirmed sedentary. The low levels of CRF measured in males and females of this HERITAGE subsample confirm that they were indeed very sedentary as a group: with a mean age of about 35 years, $\mathrm{VO}_{2} \mathrm{max} / \mathrm{kg}$ weight reached only $36 \mathrm{ml} \mathrm{O} / 2 \mathrm{~kg}$ in males and 28 in females.

Overall, steroid hormone levels were weakly associated with CRF in men but almost not at all in women. Table 6 summarizes the associations in men. Shown are partial correlations (controlling for age and ethnicity) between baseline plasma steroid hormone levels and baseline $\mathrm{VO}_{2} \mathrm{max} / \mathrm{kg}$ body weight, as well as hormonal levels (adjusted for age and ethnicity) by quartiles of fitness in men. There were substantial differences across the four quartiles of fitness, with Q1 having a mean $\mathrm{VO}_{2} \mathrm{max} / \mathrm{kg}$ weight value of $26.5(\mathrm{SD}=2.3)$ and $\mathrm{Q} 4$ a mean of $48.4(\mathrm{SD}=3.5)$. Significant partial correlations and significant differences across the four quartiles of $\mathrm{VO}_{2} \mathrm{max} / \mathrm{kg}$ weight were consistently found for ADTG, ALDO, DHT, OHPROG, SHBG, and TESTO. The patterns of differences across the fitness quartiles are depicted for DHT, OHPROG, TESTO and SHBG in Fig. 1, with indications of specific group comparison differences. Males with the lowest TESTO levels (lowest 


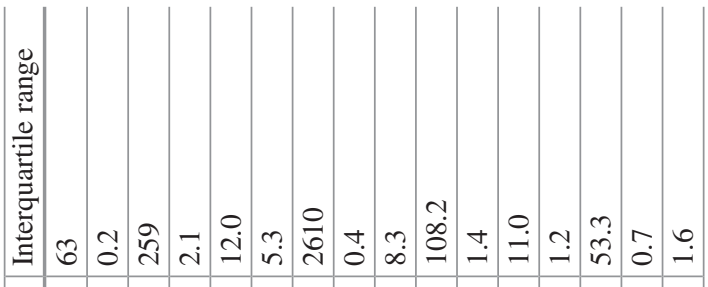

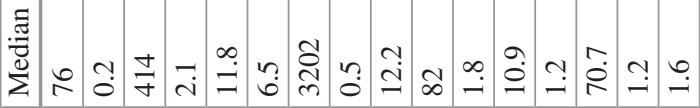

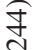

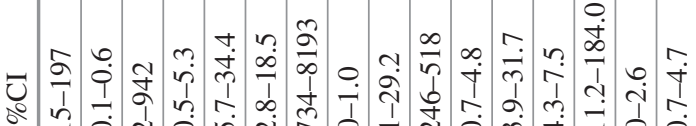
苗

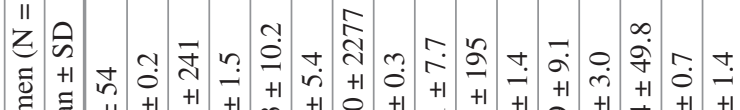

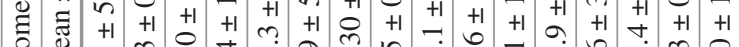

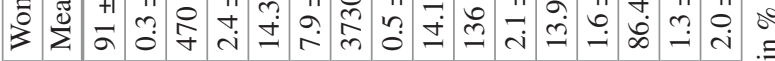

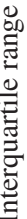

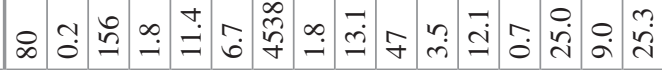

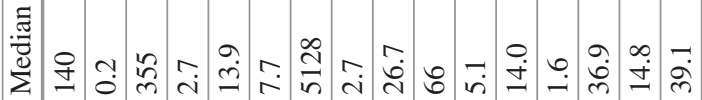
步

苞

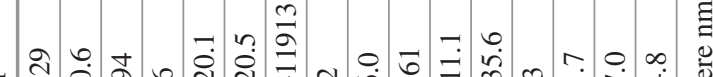

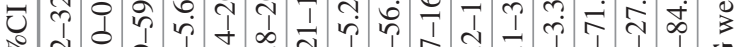
ڤ̆

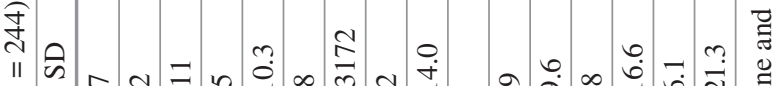

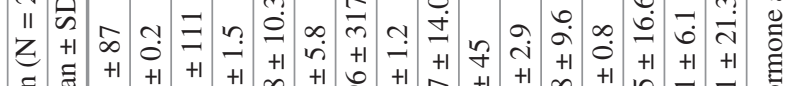

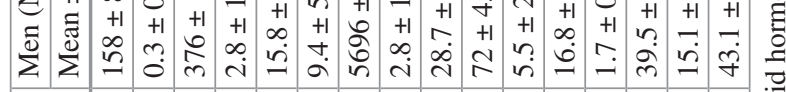
离 


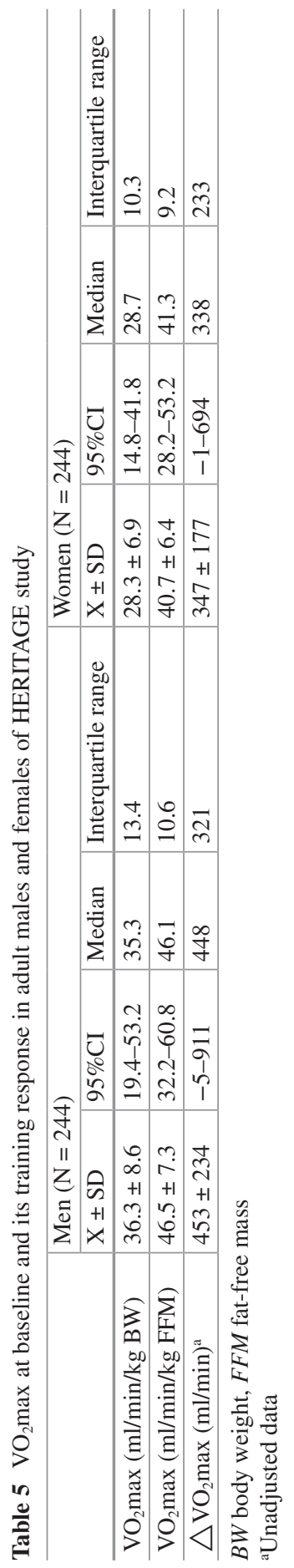




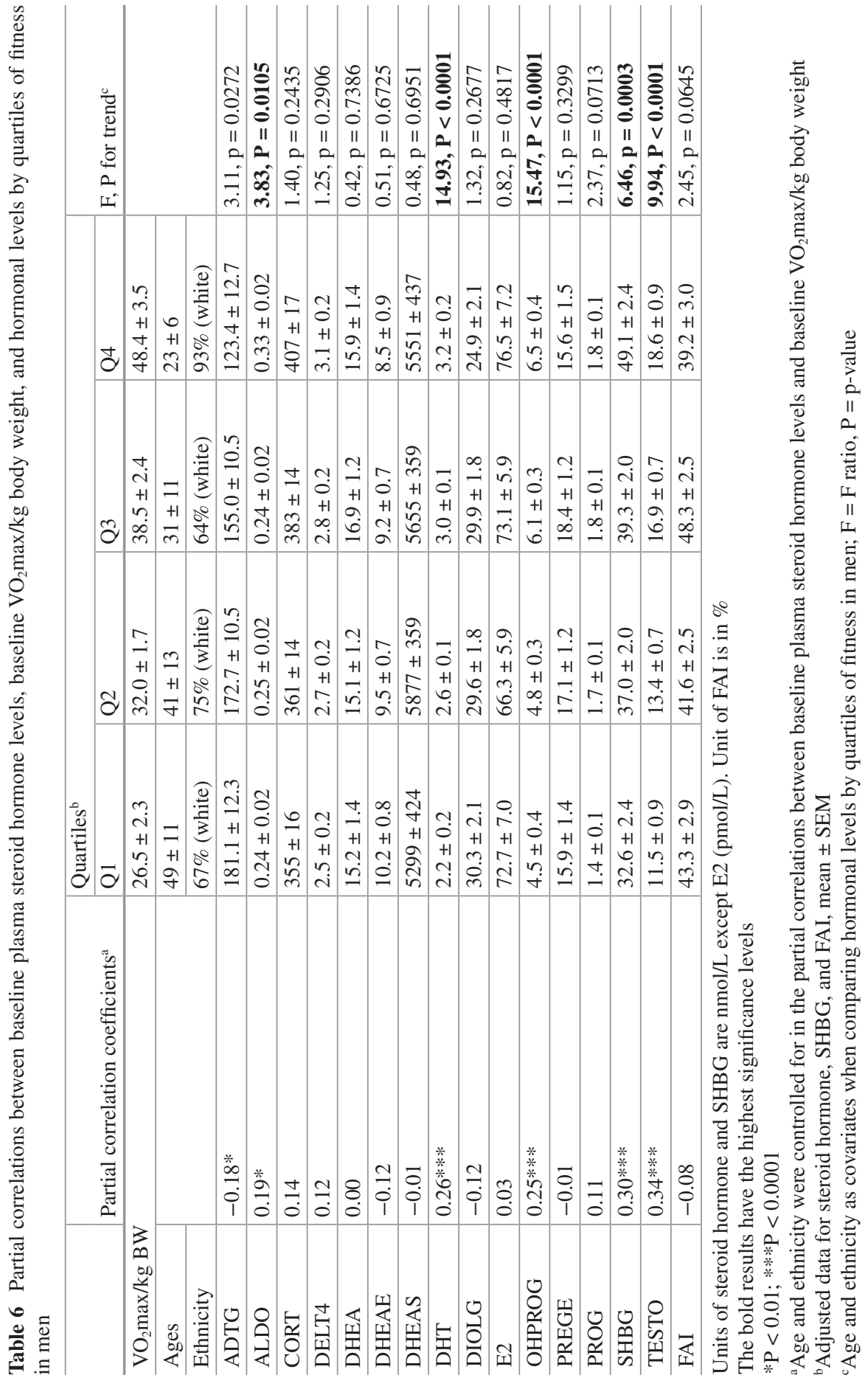




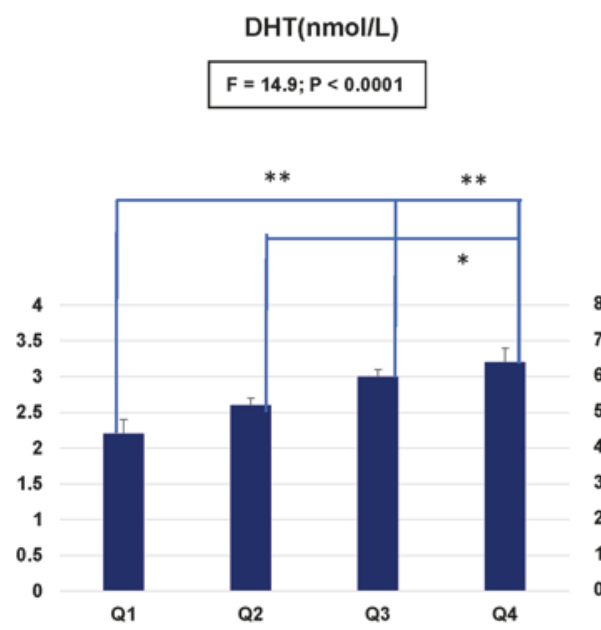

Fig 1-1

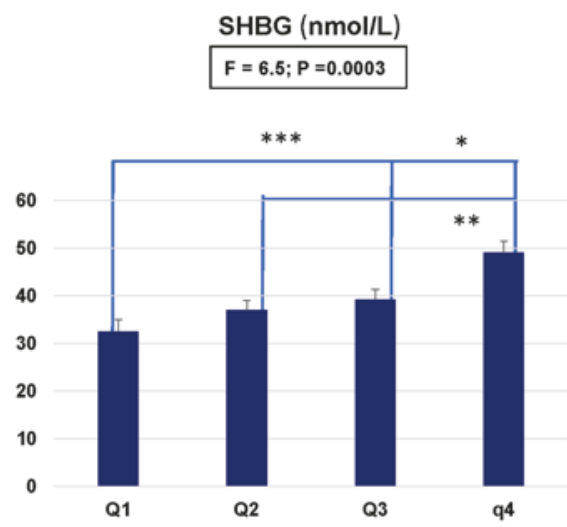

Fig 1-3

\section{OHPROG(nmol/L)}

$F=15.5 ; P<0.0001$

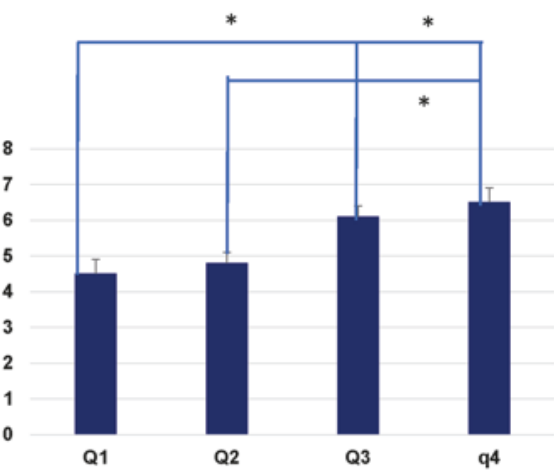

Fig 1-2

TESTO (nmol/L)

$F=9.9 ;<0.0001$

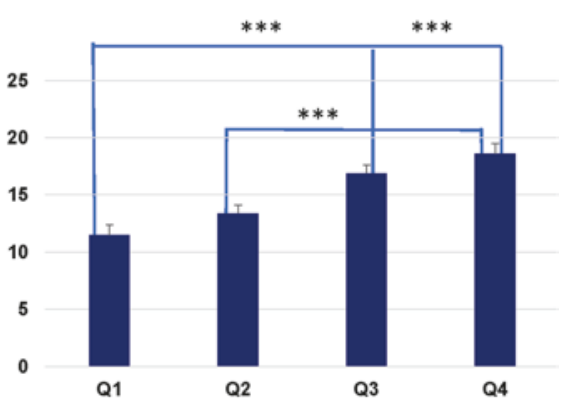

Fig 1-4

Fig. 1 Hormone levels adjusted for age and ethnicity by quartiles of baseline $\mathrm{VO}_{2} \mathrm{max} / \mathrm{kg}$ weight in men. Mean and SEM are shown. Dihydrotesterone (DHT), 17 hydroxy progesterone (OHPROG), sex hormone binding globulin (SHBG), testosterone (TESTO) $* \mathrm{P}<0.01$; $* * \mathrm{P}<0.001$; $* * * \mathrm{P}<0.0001$

$5 \%$ of the distribution; $\mathrm{N}=13$; TESTO concentration $<6.16 \mathrm{nmol} / \mathrm{L}$ ) were compared to the subjects in the upper quartile of the TESTO distribution $(\mathrm{N}=61$; TESTO concentration $>19.56 \mathrm{nmol} / \mathrm{L}$ ) for potential differences in $\mathrm{VO}_{2} \mathrm{max}$. Significant gaps in CRF were observed, with the low TESTO subjects exhibiting lower $\mathrm{VO}_{2} \mathrm{max} / \mathrm{kg} \mathrm{BW}(33.7 \pm 1.4$ vs. $39.9 \pm 0.6, \mathrm{~F}=15.2, \mathrm{P}=0.0002)$ and $\mathrm{VO}_{2} \mathrm{max} /$ kg FFM (43.9 \pm 1.3 vs. $48.3 \pm 0.6, \mathrm{~F}=9.3, \mathrm{P}=0.0032)$.

The same analyses were performed in the female sample and the results are shown in Table 7. Only FAI was significantly correlated (partial correlation) with 
Table 7 Partial correlations between baseline plasma steroid hormone levels, baseline $\mathrm{VO}_{2} \mathrm{max} / \mathrm{kg}$ body weight and hormonal levels by quartiles of fitness in women

\begin{tabular}{|c|c|c|c|c|c|c|}
\hline & \multirow{2}{*}{\begin{tabular}{|l|} 
Partial \\
correlation \\
coefficients $^{\mathrm{a}}$
\end{tabular}} & \multicolumn{4}{|l|}{ Quartiles $^{\mathrm{b}}$} & \multirow[b]{2}{*}{$\begin{array}{l}\mathrm{F}, \mathrm{P} \text { for } \\
\text { trend }^{\mathrm{c}}\end{array}$} \\
\hline & & Q1 & Q2 & Q3 & Q4 & \\
\hline \multicolumn{2}{|c|}{$\mathrm{VO}_{2} \mathrm{max} / \mathrm{kg} \mathrm{BW}$} & $19.7 \pm 2.2$ & $25.4 \pm 2.0$ & $30.7 \pm 1.3$ & $37.4 \pm 2.8$ & \\
\hline Ages & & $47 \pm 11$ & $38 \pm 13$ & $30 \pm 10$ & $23 \pm 6$ & \\
\hline Ethnicity & & $\begin{array}{l}61 \% \\
\text { (white) }\end{array}$ & $\begin{array}{l}62 \% \\
\text { (white) }\end{array}$ & $\begin{array}{l}85 \% \\
\text { (white) }\end{array}$ & $\begin{array}{l}95 \% \\
\text { (white) }\end{array}$ & \\
\hline ADTG & -0.08 & $98.3 \pm 8.1$ & $90.2 \pm 6.9$ & $91.6 \pm 6.9$ & $83.7 \pm 8.1$ & $\begin{array}{l}0.48 \\
p=0.6992\end{array}$ \\
\hline ALDO & 0.15 & $0.23 \pm 0.03$ & $0.1 \pm 0.02$ & $0.22 \pm 0.02$ & $0.32 \pm 0.03$ & $\begin{array}{l}3.68 \\
p=0.0128\end{array}$ \\
\hline CORT & 0.14 & $409.3 \pm 35$ & $442 \pm 29$ & $525 \pm 29$ & $505 \pm 34$ & $\begin{array}{l}1.95 \\
\mathrm{p}=0.1215\end{array}$ \\
\hline DELT4 & 0.05 & $2.2 \pm 0.2$ & $2.5 \pm 0.2$ & $2.3 \pm 0.2$ & $2.5 \pm 0.2$ & $\begin{array}{l}0.48 \\
\mathrm{p}=0.6975\end{array}$ \\
\hline DHEA & 0.01 & $14.9 \pm 1.4$ & $14.6 \pm 1.2$ & $13.3 \pm 1.2$ & $14.6 \pm 1.4$ & $\begin{array}{l}0.36 \\
p=0.7841\end{array}$ \\
\hline DHEAE & -0.06 & $9.3 \pm 0.8$ & $8.5 \pm 0.7$ & $6.2 \pm 0.7$ & $7.5 \pm 0.8$ & $\begin{array}{l}2.72 \\
p=0.0452\end{array}$ \\
\hline DHEAS & -0.04 & $3954 \pm 314$ & $3843 \pm 265$ & $3455 \pm 265$ & $3667 \pm 312$ & $\begin{array}{l}0.49 \\
P=0.6919\end{array}$ \\
\hline DHT & -0.04 & $0.54 \pm 0.04$ & $0.59 \pm 0.03$ & $0.48 \pm 0.03$ & $0.48 \pm 0.04$ & $\begin{array}{l}2.19 \\
p=0.0897\end{array}$ \\
\hline DIOLG & -0.08 & $15.1 \pm 1.2$ & $14.9 \pm 1.0$ & $13.6 \pm 1.0$ & $12.6 \pm 1.2$ & $\begin{array}{l}1.25 \\
p=0.2922\end{array}$ \\
\hline E2 & -0.04 & $155 \pm 31$ & $132 \pm 26$ & $150 \pm 26$ & $107 \pm 30$ & $\begin{array}{l}2.46 \\
p=0.0636\end{array}$ \\
\hline OHPROG & 0.02 & $2.4 \pm 0.2$ & $1.8 \pm 0.2$ & $1.8 \pm 0.2$ & $2.1 \pm 0.2$ & $\begin{array}{l}2.06 \\
p=0.1064\end{array}$ \\
\hline PREGE & -0.05 & $16.1 \pm 1.4$ & $14.1 \pm 1.2$ & $12.1 \pm 1.2$ & $13.4 \pm 1.4$ & $\begin{array}{l}1.43 \\
p=0.2353\end{array}$ \\
\hline PROG & -0.02 & $2.2 \pm 0.5$ & $1.5 \pm 0.4$ & $1.2 \pm 0.4$ & $1.4 \pm 0.5$ & $\begin{array}{l}0.79 \\
p=0.5002\end{array}$ \\
\hline SHBG & 0.14 & $66.7 \pm 7.8$ & $86.0 \pm 6.6$ & $101.3 \pm 6.6$ & $91.7 \pm 7.7$ & $\begin{array}{l}3.41 \\
\mathrm{p}=0.0183\end{array}$ \\
\hline TESTO & -0.04 & $1.3 \pm 0.1$ & $1.4 \pm 0.1$ & $1.3 \pm 0.1$ & $1.2 \pm 0.1$ & $\begin{array}{l}1.01 \\
\mathrm{p}=0.3889\end{array}$ \\
\hline FAI & $-0.20^{*}$ & $2.6 \pm 0.2$ & $2.2 \pm 0.2$ & $1.5 \pm 0.2$ & $1.5 \pm 0.2$ & $\begin{array}{l}4.45 \\
p=0.0046\end{array}$ \\
\hline
\end{tabular}

Units of steroid hormone and SHBG are nmol/L except E2 (pmol/L). Unit of FAI is in \% $* \mathrm{P}<0.01$

${ }^{\mathrm{a}} \mathrm{Age}$ and ethnicity as adjustment factors for partial correlation between baseline plasma steroid hormone levels and baseline $\mathrm{VO}_{2} \mathrm{max} / \mathrm{kg}$ body weight

${ }^{\mathrm{b}}$ Adjusted data for steroid hormone, SHBG, and FAI, mean \pm SEM

${ }^{\mathrm{c}}$ Age and ethnicity as covariance when comparing hormonal levels by quartiles of fitness in women; $\mathrm{F}=\mathrm{F}$ ratio, $\mathrm{P}=\mathrm{p}$-value 
Fig. 2 Free androgen index (FAI) adjusted for age and ethnicity by quartiles of baseline $\mathrm{VO}_{2} \mathrm{max} / \mathrm{kg}$ weight in women. Mean and SEM are shown. $\underline{\mathrm{F}=4.5}$; $* \mathrm{P}=0.05$

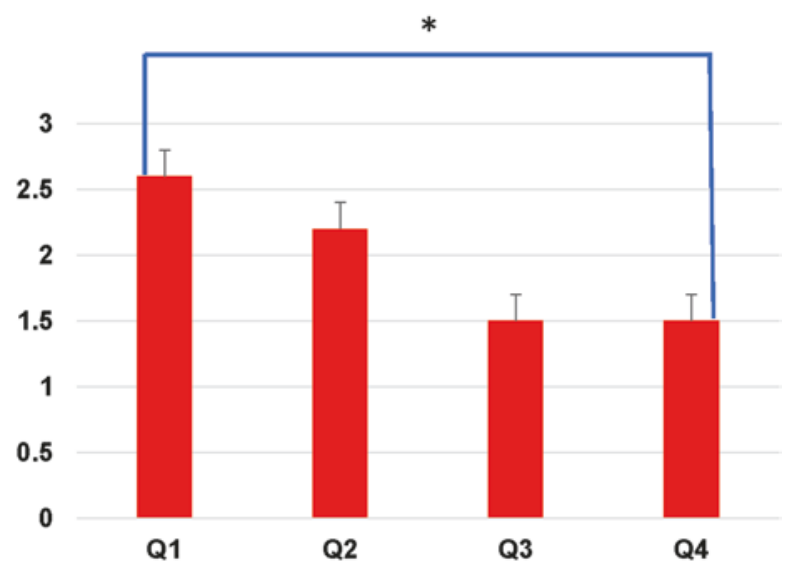

baseline $\mathrm{VO}_{2} \mathrm{max} / \mathrm{kg}$ weight and differed across the four fitness groups. None of the hormones was consistently associated with fitness in women. The FAI values across the four fitness quartiles are depicted in Fig. 2.

Baseline plasma steroid levels, SHBG concentrations and FAI were not associated with the gains in $\mathrm{VO}_{2}$ max resulting from exposure to the 20-week aerobic exercise program in men or in women. For the latter analyses, the gains in $\mathrm{VO}_{2}$ max in $\mathrm{mlO}_{2}$ were adjusted for baseline level, age and ethnicity. Notably, the men in the low TESTO group (lowest $5 \%$ of the distribution) did not show a deficit in CRF responsiveness to exercise training (results not shown).

\section{Discussion}

The present study is the most comprehensive report published to date on the relationships between a large panel of plasma steroid hormones and CRF in sedentary men and women at baseline and in response to a fully standardized and monitored 20-week exercise program. Of particular significance, the plasma concentrations of steroid hormones were measured twice in the morning in a fasted state (samples from two different days) before and again twice (from samples obtained on 2 days) after the exercise training program. Also of significance, all blood samples were drawn in the early follicular phase of the menstrual cycle for eumenorrheic women. Furthermore, three quality-control studies were implemented to quantify the magnitude of the assay variance and the within-individual day-to-day variation in hormone concentrations. As a large number of tests of significance were performed, an alpha threshold of $\mathrm{p}<0.01$ was used to reduce the risk of false positive results.

Significant associations were found by partial correlation analyses between baseline $\mathrm{VO}_{2} \mathrm{max} / \mathrm{kg}$ weight and plasma levels of ADTG, ALDO, DHT, OHPROG, SHBG, and TESTO in men. In contrast, in women, only the FAI was significantly associated with baseline $\mathrm{VO}_{2}$ max/kg weight. When comparing steroids, SHBG and 
FAI across quartiles of baseline $\mathrm{VO}_{2} \mathrm{max} \mathrm{ml} / \mathrm{kg}$ weight, the plasma concentration of DHT, OHPROG, SHBG, and TESTO increased gradually from Q1 to Q4 in men whereas FAI progressively decreased as fitness increased in women, indicating that a higher level of TESTO was associated with better CRF. Indeed, once the effects of age and ethnicity were taken into account, TESTO explained about $3 \%$ of the variance in baseline $\mathrm{VO}_{2} \mathrm{max} / \mathrm{kg}$ weight in men. In females, FAI also accounted for about $3 \%$ of the baseline $\mathrm{VO}_{2} \mathrm{max} / \mathrm{kg}$ weight, with the same statistical control over age and ethnicity. Baseline plasma steroid levels, SHBG concentrations or FAI were not associated with the gains in $\mathrm{VO}_{2}$ max resulting from exposure to the 20-week aerobic exercise program after adjustment for baseline values, age and ethnicity.

The present results reinforce the idea that $\mathrm{SHBG}^{3}$ and TESTO (Storer et al. 2016) are weakly correlated with baseline fitness. In the CARDIA Male Hormone Study (391 blacks and 604 whites, aged 24-32 years), SHBG was significantly $(p=0.05)$ associated with estimated CRF among white men, with quartiles four and two having the highest $(33.5 \mathrm{nmol} / \mathrm{L})$ and lowest $(27.8 \mathrm{nmol} / \mathrm{L})$ SHBG concentrations, respectively (Wolin et al. 2007). TESTO supplementation in mobility-limited older men $(\mathrm{n}=64)$ increased hemoglobin and attenuated the age-related declines in $\mathrm{VO}_{2}$ peak (Storer et al. 2016). However, our results also contradict those of other reports. Lucertini et al. (2015) found basal CORT levels were lower in the high-fit $\left(\mathrm{VO}_{2} \mathrm{max}\right.$, $37.9 \pm 0.9 \mathrm{ml} / \mathrm{kg} / \mathrm{min})$ than the low-fit group $\left(\mathrm{VO}_{2} \mathrm{max}, 26.4 \pm 0.7 \mathrm{ml} / \mathrm{kg} / \mathrm{min}\right)$. We could not herein confirm the relationship between CORT and fitness. This discrepancy may be explained by the basic characteristics of the study designs: for instance, $\mathrm{VO}_{2}$ max was estimated using the Rockport Walking Test in the study of Lucertini et al. (2015), the sample size of their study was quite small and subjects were older ( $n=22$, mean age 68 years), and CORT was assayed from saliva samples obtained at 18:00, late afternoon. Huang et al. also did not find a difference in CORT between high-fitness $\left(\mathrm{VO}_{2} \max , 51.0 \pm 0.8, \mathrm{ml} / \mathrm{kg} / \mathrm{min}\right.$, ages: $\left.22.3 \pm 1.97, \mathrm{n}=7\right)$ and lowfitness groups $\left(\mathrm{VO}_{2} \max , 36.3 \pm 1.3, \mathrm{ml} / \mathrm{kg} / \mathrm{min}\right.$, ages, $\left.20.9 \pm 0.8, \mathrm{n}=7\right)$ in males (Huang et al. 2014).

The World Anti-Doping Agency (WADA) has developed a specific steroid module as a part of their Athlete Biological Passport (ABP; Alladio et al. 2016), which was implemented internationally in January 2014. Anabolic steroids represent the most abundant class of substance used to enhance performance in elite sports. Anabolic steroids are generally used to enhance muscle mass and muscular strength or power. Their use for improvement of endurance performance or recovery from training is less frequent. Our three quality control studies of plasma levels of steroids revealed that their blood concentrations were quite stable within an individual. We observed that TESTO and DHT were weakly but positively associated with CRF in men only. These associations were lost when $\mathrm{VO}_{2} \max$ was adjusted for fat-free mass (results not shown here), suggesting that the associations with fitness may have been mediated by the muscle mass and not by the ability to deliver oxygen (cardiac output and hemoglobin content of blood) to the working muscle. Importantly, there was no relation between plasma levels of steroids and the $\mathrm{VO}_{2} \mathrm{max}$ training response to the HERITAGE exercise program. Globally, our results provide little support for a substantial role of high plasma steroids content in CRF and endurance performance. 
We conclude from our detailed observations that baseline plasma steroid levels are only weakly associated with individual differences in CRF in the sedentary state in men, whereas no association could be detected with trainability, as defined by the change in $\mathrm{VO}_{2}$ max with the exercise program. The associations are particularly consistent for the plasma concentrations of testosterone and SHBG. In women, the most consistent association pattern was seen with the FAI, potentially reflecting the fact that high levels of free testosterone in females could be associated with slightly elevated CRF.

Acknowledgments The HERITAGE Family Study has been supported over the years by multiple grants from the National Institute for Heart, Lung and Blood Diseases of the National Institutes of Health (HL45670, C. Bouchard and T. Rankinen; HL47323, A.S. Leon; HL47317, D.C. Rao; HL47327, J.S. Skinner; HL47321, J.H. Wilmore, deceased). CB is partially funded by the John W. Barton Sr. Chair in Genetics and Nutrition. Zihong HE is funded by the China Scholarship Council (File No. 201603620001) and China Institute of Sport Science (2015-01, 2016-01). We would like to express our gratitude to Dr. Alain Belanger (retired) and his staff from the Molecular Endocrinology Laboratory of the Laval University Medical Center in Quebec City, Canada, for the assays of the steroids and their dedication to the HERITAGE Family Study.

Disclosures AT receives research funding from Johnson \& Johnson Medical Companies for studies unrelated to the present paper.

\section{References}

Alladio E, Caruso R, Gerace E, Amante E, Salomone A, Vincenti M (2016) Application of multivariate statistics to the steroidal module of the athlete biological passport: a proof of concept study. Anal Chim Acta 922:19-29

Bouchard C, Leon AS, Rao DC, Skinner JS, Wilmore JH, Gagnon J (1995) The HERITAGE family study. Aims, design, and measurement protocol. Med Sci Sports Exerc 27:721-729

Bouchard C, Blair SN, Katzmarzyk PT (2015) Less sitting, more physical activity, or higher fitness? Mayo Clin Proc 90:1533-1540

Bruder-Nascimento T, Ferreira NS, Zanotto CZ, Ramalho F, Pequeno IO, Olivon VC, Neves KB, Alves-Lopes R, Campos E, Silva CA, Fazan R, Carlos D, Mestriner FL, Prado D, Pereira FV, Braga T, Luiz JP, Cau SB, Elias PC, Moreira AC, Camara NO, Zamboni DS, Alves-Filho JC, Tostes RC (2016) NLRP3 inflammasome mediates aldosterone-induced vascular damage. Circulation 134:1866-1880

Canoy D, Barber TM, Pouta A, Hartikainen AL, McCarthy MI, Franks S, Jarvelin MR, Tapanainen JS, Ruokonen A, Huhtaniemi IT, Martikainen H (2014) Serum sex hormone-binding globulin and testosterone in relation to cardiovascular disease risk factors in young men: a populationbased study. Eur J Endocrinol 170:863-872

Couillard C, Gagnon J, Bergeron J, Leon AS, Rao DC, Skinner JS, Wilmore JH, Despres JP, Bouchard C (2000) Contribution of body fatness and adipose tissue distribution to the age variation in plasma steroid hormone concentrations in men: the HERITAGE family study. J Clin Endocrinol Metab 85:1026-1031

Engberg E, Alen M, Kukkonen-Harjula K, Peltonen JE, Tikkanen HO, Pekkarinen H (2012) Life events and change in leisure time physical activity: a systematic review. Sports Med 42:433-447 
Ennour-Idrissi K, Maunsell E, Diorio C (2015) Effect of physical activity on sex hormones in women: a systematic review and meta-analysis of randomized controlled trials. Breast Cancer Res 17:139

Group ECW (2006) Hormones and cardiovascular health in women. Hum Reprod Update 12:483-497

Haddock BL, Marshak HP, Mason JJ, Blix G (2000) The effect of hormone replacement therapy and exercise on cardiovascular disease risk factors in postmenopausal women. Sports Med 29:39-49

Hammond GL (2016) Plasma steroid-binding proteins: primary gatekeepers of steroid hormone action. J Endocrinol 230:R13-R25

Hasan KM, Rahman MS, Arif KM, Sobhani ME (2012) Psychological stress and aging: role of glucocorticoids (GCs). Age 34:1421-1433

Huang CJ, Webb HE, Beasley KN, McAlpine DA, Tangsilsat SE, Acevedo EO (2014) Cardiorespiratory fitness does not alter plasma pentraxin 3 and cortisol reactivity to acute psychological stress and exercise. Appl Physiol Nutr Metab 39:375-380

Kim JW, Kim DY (2012) Effects of aerobic exercise training on serum sex hormone binding globulin, body fat index, and metabolic syndrome factors in obese postmenopausal women. Metab Syndr Relat Disord 10:452-457

Kohl HW 3rd, Craig CL, Lambert EV, Inoue S, Alkandari JR, Leetongin G, Kahlmeier S, Lancet Physical Activity Series Working G (2012) The pandemic of physical inactivity: global action for public health. Lancet 380:294-305

Kumagai H, Zempo-Miyaki A, Yoshikawa T, Tsujimoto T, Tanaka K, Maeda S (2016) Increased physical activity has a greater effect than reduced energy intake on lifestyle modificationinduced increases in testosterone. J Clin Biochem Nutr 58:84-89

Labrie F (2015) All sex steroids are made intracellularly in peripheral tissues by the mechanisms of intracrinology after menopause. J Steroid Biochem Mol Biol 145:133-138

Lee IM, Shiroma EJ, Lobelo F, Puska P, Blair SN, Katzmarzyk PT, Lancet Physical Activity Series Working G (2012) Effect of physical inactivity on major non-communicable diseases worldwide: an analysis of burden of disease and life expectancy. Lancet 380:219-229

Lother A, Moser M, Bode C, Feldman RD, Hein L (2015) Mineralocorticoids in the heart and vasculature: new insights for old hormones. Annu Rev Pharmacol Toxicol 55:289-312

Lucertini F, Ponzio E, Di Palma M, Galati C, Federici A, Barbadoro P, D’Errico MM, Prospero E, Ambrogini P, Cuppini R, Lattanzi D, Minelli A (2015) High cardiorespiratory fitness is negatively associated with daily cortisol output in healthy aging men. PLoS One 10:e0141970

Luu-The V, Labrie F (2010) The intracrine sex steroid biosynthesis pathways. Prog Brain Res 181:177-192

Meyer MR, Barton M (2016) Estrogens and coronary artery disease: new clinical perspectives. Adv Pharmacol 77:307-360

Meyer EJ, Nenke MA, Rankin W, Lewis JG, Torpy DJ (2016) Corticosteroid-binding globulin: a review of basic and clinical advances. Hormon-Stoffwechselforsch 48:359-371

Nicolaides NC, Kyratzi E, Lamprokostopoulou A, Chrousos GP, Charmandari E (2015) Stress, the stress system and the role of glucocorticoids. Neuroimmunomodulation 22:6-19

Pongkan W, Chattipakorn SC, Chattipakorn N (2016) Roles of testosterone replacement in cardiac ischemia-reperfusion injury. J Cardiovasc Pharmacol Ther 21:27-43

Reslan OM, Khalil RA (2012) Vascular effects of estrogenic menopausal hormone therapy. Rev Recent Clin Trials 7:47-70

Sarzynski MA, Ghosh S, Bouchard C (2016) Genomic and transcriptomic predictors of response levels to endurance exercise training. J Physiol. https://doi.org/10.1113/JP272559

Sato K, Lemitsu M (2015) Exercise and sex steroid hormones in skeletal muscle. J Steroid Biochem Mol Biol 145:200-205

Sato K, Lemitsu M, Matsutani K, Kurihara T, Hamaoka T, Fujita S (2014) Resistance training restores muscle sex steroid hormone steroidogenesis in older men. FASEB J 28:1891-1897 
Singh R, Artaza JN, Taylor WE, Braga M, Yuan X, Gonzalez-Cadavid NF, Bhasin S (2006) Testosterone inhibits adipogenic differentiation in 3T3-L1 cells: nuclear translocation of androgen receptor complex with beta-catenin and T-cell factor 4 may bypass canonical Wnt signaling to down-regulate adipogenic transcription factors. Endocrinology 147:141-154

Sinha-Hikim I, Taylor WE, Gonzalez-Cadavid NF, Zheng W, Bhasin S (2004) Androgen receptor in human skeletal muscle and cultured muscle satellite cells: up-regulation by androgen treatment. J Clin Endocrinol Metab 89:5245-5255

Siri WE (1956) The gross composition of the body. Adv Biol Med Phys 4:239-280

Skinner JS, Wilmore KM, Krasnoff JB, Jaskolski A, Jaskolska A, Gagnon J, Province MA, Leon AS, Rao DC, Wilmore JH, Bouchard C (2000) Adaptation to a standardized training program and changes in fitness in a large, heterogeneous population: the HERITAGE Family Study. Med Sci Sports Exerc 32:157-161

Skinner JS, Jaskolski A, Jaskolska A, Krasnoff J, Gagnon J, Leon AS, Rao DC, Wilmore JH, Bouchard C, Study HF (2001) Age, sex, race, initial fitness, and response to training: the HERITAGE Family Study. J Appl Physiol 90:1770-1776

Storer TW, Bhasin S, Travison TG, Pencina K, Miciek R, McKinnon J, Basaria S (2016) Testosterone attenuates age-related fall in aerobic function in mobility limited older men with low testosterone. J Clin Endocrinol Metab 101:2562-2569

Ukkola O, Gagnon J, Rankinen T, Thompson PA, Hong Y, Leon AS, Rao DC, Skinner JS, Wilmore JH, Bouchard C (2001) Age, body mass index, race and other determinants of steroid hormone variability: the HERITAGE Family Study. Eur J Endocrinol 145:1-9

United States Department of Health and Human Services (2008) 2008 physical activity guidelines for Americans: be active, healthy, and happy! U.S. Dept. of Health and Human Services, Washington, DC

Wilmore JH, Stanforth PR, Domenick MA, Gagnon J, Daw EW, Leon AS, Rao DC, Skinner JS, Bouchard C (1997) Reproducibility of anthropometric and body composition measurements: the HERITAGE Family Study. Intl J Obes Rel Metab Disord 21:297-303

Wolin KY, Colangelo LA, Liu K, Sternfeld B, Gapstur SM (2007) Associations of androgens with physical activity and fitness in young black and white men: the CARDIA Male Hormone Study. Prev Med 44:426-431

Open Access This chapter is licensed under the terms of the Creative Commons Attribution 4.0 International License (http://creativecommons.org/licenses/by/4.0/), which permits use, sharing, adaptation, distribution and reproduction in any medium or format, as long as you give appropriate credit to the original author(s) and the source, provide a link to the Creative Commons license and indicate if changes were made.

The images or other third party material in this chapter are included in the chapter's Creative Commons license, unless indicated otherwise in a credit line to the material. If material is not included in the chapter's Creative Commons license and your intended use is not permitted by statutory regulation or exceeds the permitted use, you will need to obtain permission directly from the copyright holder.

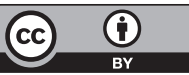

